\title{
Performance Monitoring, Supervisory Support, and Job Characteristics and Their Impact on Employee Well-Being Amongst Four Samples of Call Centre Agents in South Africa
}

\author{
James Fisher, Karen Miller, and Andrew Thatcher \\ Discipline of Psychology, School of Human \& Community Development, University of the \\ Witwatersrand, Johannesburg, P.O. WITS 2050, South Africa \\ James.Fisher@wits.ac.za
}

\begin{abstract}
This paper reports a descriptive comparison of selected aspects of work experience reflected by four groups of employees drawn from four contrasting call center environments based in the Gauteng Province of South Africa. The call centers were selected as representing distinct business and management practices in terms of the envisioned market and the service model enacted within each call center. Participants were call center agents who completed a questionnaire survey of aspects of their work life experiences and context free life satisfaction. In addition, interviews were conducted with supervisors in each call center to assess supervisory practice, and some follow up interviews were conducted with call centre agents. Findings do not fit neatly into a Tayloristic-Empowerment continuum, but rather point to a more complex balance between the unfavorable work demands experienced and wider feelings of self worth. Implications for job design and enhanced well being are summarized.
\end{abstract}

Keywords: Call Centers. Job Design. Electronic Performance Monitoring. Well-Being.

\section{Introduction}

South African management practices have a historic disposition towards control and Taylorism, as part of the practice and legacy of apartheid social structuring and education [1]. The emphasis on production and control has been largely shaped by the need to harness a low skilled, poorly educated workforce by breaking work down into manageable units and retaining strong supervisory direction. This historic disposition creates vulnerability that technologies like those that underpin call centres will follow what has been termed the mass service call centre model [2]. In this classification call centre management and work demands can be placed on a continuum from 'Tayloristic' at one end, to 'Empowerment' at the other [3]. Low skill levels, highly repetitive tasks and monotony characterise Tayloristic call centre work environments, whilst Empowered call centre environments involve professionals who have a high 
level of job control and varied skill demands. The general assumption is that as the work environment migrates to the Tayloristic end of the continuum it will re-percuss in poor feelings of satisfaction and well-being on the part of employees, whilst Empowered work environments should evoke greater feelings of satisfaction accomplishment and self worth [4].

The usual connotation with the Tayloristic-Empowerment continuum is that at the Empowerment end, call center agents will possess a higher level of education or technical qualification or skill and will be engaged in more flexible interaction with callers; practicing their skills over a wide range of problems and being challenged to extend their problem solving skills as a consequence of this richer engagement of clients' problems. At the Tayloristic end of the continuum, caller-agent exchanges are brief and highly structured; often agents work from pre prepared scripts on the presumption that caller questions and problems are highly standardised. When unusual problems are presented by callers, the expectation is that these should be referred to supervisors or another better qualified colleague. Little encouragement is given to interaction with co-workers and enhanced problem solving strategies is not encouraged. The emphasis is on high volume, short duration interactions with clients.

However this neat conceptualisation is not so clear cut [5]. Some massed service call centers adopt practices that in this conceptualisation would be associated with the high commitment work practices normally associated with the Empowerment end of the continuum, whilst some high commitment service call centers adopt mass market high intensity monitoring [6] [7].

Our interest in this research is to see whether the latent scientific management appeal that call center technology might have to the South African tradition of control and authority manifests itself in the adoption of supervisory and management practices so widely associated with massed service model - even though the nature of the call center business more reflects the needs of a high service model.

This paper reports research conducted in four call centers drawn from four contrasting organisations in Gauteng, South Africa. Each call centre represents a contrasting use of call center technology in that they occupy a different role in their organisation's business model and client servicing strategy. Two of the call centers are directed at servicing the technical needs of retail clients, one directed at trade clients (Call Center A; $n=27$ ), one directed at retail clients (Call Center B; $n=38$ ), and these represent the Empowerment end of the continuum. The other two are directed at mass volume client service. Both are in the financial services sector. One of these has structured their employee-client interaction on the basis of prepared scripts (Call Center D; n=33), whilst the other does not (Call Center C; $=42$ ) and these represent the Tayloristic end of the continuum. Thus, based on the parameters of the likely need to use flexibility of knowledge in problem solving as part of agent-customer interactions, a reasonable expectation in terms of levels of control and regulation in work design would be $\mathrm{A}<\mathrm{B}<\mathrm{C}<\mathrm{D}$.

Details of these samples are set out in section 4 of this paper which presents a summary of the main findings. 


\section{Aim}

The aim of the present research is, using the inherent contrasts in work design presented by the four call centers, to measure, describe and compare the relationships between the key job design features of performance monitoring, supervisory support, the role of performance feedback, and the dimensions of work as assessed by the Job Characteristics Inventory subscales of Skill Variety, Autonomy, Task Identity, Feedback, Dealing with Others, and Friendship Opportunities and dependent measures of employee well-being as characterized by the work related measures of Intrinsic and Extrinsic Job Satisfaction, and the context free measures of well-being of Life Satisfaction and Self Esteem.

\section{Methodology}

Agents in each call center were volunteer participants and were asked to take part in the study, in full confidentiality and anonymity, by completing a questionnaire that comprised the following sections;

\subsection{Biographic Information}

Biographic information collected consisted of answers to specified questions about age (in years), sex, marital status, number of dependents, employment history (including tenure in the present job), and education attainment.

\subsection{Job Design}

Respondents were asked to complete a set of sub sections on the questionnaire to allow identification of core characteristics of their current job. All Items were responded to using a five point scale. The sub sections were;

Performance Monitoring. Respondents' satisfaction with performance monitoring was measured using the Satisfaction with Computer Monitoring Scale [8] Cronbach's alpha coefficient for the combined samples in this study for the measure was 0.86 .

Supervisory Support. Respondents' satisfaction with their level of perceived supervisory support was measured using items 4, 12, 17 and 24 from Module 5 of the Michigan Organisational Assessment Questionnaire [9]. Cronbach's alpha coefficient for the combined samples in this study for the measure was 0.78 .

Performance Feedback. Respondents' experiences as to whether the feedback that they receive from their supervisors was constructive, formative/ developmental and, supportive was measured using a three item scale developed for the purpose, thereby being more focussed that items in the Supervisory support and JCI measures. Cronbach's alpha coefficient for the combined samples in this study for the measure was 0.89 .

Consultation about Job Content. Respondents' satisfaction with extent, frequency and type of consultation about job content was measured using a three item scale 
developed for the purpose, thereby being more focussed that items in the Supervisory support and JCI measures. Cronbach's alpha coefficient for the combined samples in this study for the measure was 0.80 .

Consultation about Technology Purchase. Respondents' satisfaction with the extent, timing and type of consultation about the purchase of the call center technology that they use was measured using a three item scale developed for the purpose. Cronbach's alpha coefficient for the combined samples in this study for the measure was 0.67 .

Job Characteristics. Respondents' feelings about the content of their job was assessed using the six dimensions of the Job Characteristics Inventory [10] Cronbach's alpha coefficient for the combined samples in this study for the global measure was 0.78 ;

Skill Variety (the extent to which a job requires a variety of employee competencies to carry it out), Cronbach's alpha coefficient for the combined samples in this study for the measure was 0.71 ;

Task Identity (the extent to which the job requires an employee to complete a whole piece of work from start to finish), Cronbach's alpha coefficient for the combined samples in this study for the measure was 0.68 ;

Autonomy (the extent to which the employee has discretion in carrying out tasks), Cronbach's alpha coefficient for the combined samples in this study for the measure was 0.75 ;

Dealing with Others (the degree to which the job requires employees to deal with others to complete tasks), Cronbach's alpha coefficient for the combined samples in this study for the measure was 0.81 ;

Friendship Opportunities (the degree to which the job requires employees to talk with one another on the job and establish informal relationships with other employees at work), Cronbach's alpha coefficient for the combined samples in this study for the measure was 0.77 ;

Feedback. The degree to which employees receive information as they work which reveals how well they are performing their tasks), Cronbach's alpha coefficient for the combined samples in this study for the measure was 0.69 .

\subsection{Well-Being}

Respondents were then asked to complete a set of sub sections of the questionnaire to allow assessment of three different aspects of their well-being. Again, all Items were responded to using a five point scale. The sub sections were;

Job Satisfaction. This was assessed by using the Global Job Satisfaction Scale [11] and the integral measures of Intrinsic and Extrinsic Job Satisfaction. Cronbach's alpha coefficient for the combined samples in this study for the global measure was 0.87 . 
Life Satisfaction. This was assessed by using the Satisfaction with Life Scale [12]. Cronbach's alpha coefficient for the combined samples in this study for the measure was 0.82 .

Self Esteem. This was assessed by using Self Esteem Scale [13]. Cronbach's alpha coefficient for the combined samples in this study for the measure was 0.90 .

\subsection{Interviews}

In addition two sets of short, semi-structured interviews were conducted; one set with supervisors at each participating call center and the other set as follow up interviews with a small sub-set of participating call center agents.

Interviews with Supervisors. These were conducted to ascertain their judgement of; their role as supervisor, the planned and intended use of performance monitoring data, the use of feedback of performance data to call center agents, and their judgement about the general quality of work life for call center agents in their call center.

Interviews with Call Center Agents. Supplementary post questionnaire follow up interviews were conducted with sub samples of participant call center agents at each of the four call centres to add to the researchers' general understanding of work demands and experiences.

\subsection{History and Local History Effects}

In order to minimise history effects and local history effects [14], all data gathering took place during a period of four months characterised by economic growth and high business confidence. None of the participating organisations had recently been involved in take-overs, mergers, downsizing exercises or other large-scale events that might shape the general outlook to job experiences and work related well-being. All participants were informed of the outcomes of the research.

\section{Findings}

As can be appreciated, the procedure yielded a mass of data; much of which, though of value in characterising the sample need not be reported here. Rather the principle findings are summarised in the following sections.

\subsection{Biographical Data}

Notable are the similarities in age and tenure across call centers (standard deviations and ranges not reported here) but there are sizable differences in employment history, with technical service call center (A and B) employees having had shorter working lives and fewer previous jobs.

Technical service call centers samples (A and B) were male dominated, with fewer married and smaller numbers of dependents. Mass service call centers (C and D) reflected a broadly equal number of males and females, with an equal proportion of married and number of dependents (not reported here). Educational qualifications 
Table 1. Biographic data (main data only)

\begin{tabular}{lrrrr}
\hline Variable & \multicolumn{4}{c}{ Call Center } \\
& $\mathrm{A}(\mathrm{n}=27)$ & $\mathrm{B}(\mathrm{n}=38)$ & $\mathrm{C}(\mathrm{n}=42)$ & $\mathrm{D}(\mathrm{n}=33)$ \\
\hline Age (Years) & 26.4 & 24.3 & 28.4 & 27.9 \\
Work Exp. (Years) & 6.2 & 5.1 & 10.6 & 10.1 \\
Tenure (Years) & 3.7 & 3.0 & 4.2 & 4.3 \\
Sex (\% Female) & 6 & 11 & 62 & 58 \\
Maried/ Partner (\%) & 17 & 12 & 76 & 69 \\
\hline
\end{tabular}

were patterned differently with technical service call centers preferring staff with a national technical certificate background whilst mass service call centers showing a higher level of matriculated employees (84\%) and a high proportion $(27 \%)$ of graduates in the samples.

\subsection{Interviews with Supervisors}

Supervisor interviews revealed that each in each of the four call centers, irrespective of the core focus of the business, supervisors reflected the view that their engagement with agents was supportive, concerned with staff development and productivity as equal priority, that performance monitoring was as much for staff development as it was for quality assurance and meeting productivity goals, and performance feedback was supportive, developmental and "correctional".

For all four call centers, supervisor's views of the qualitiy of work life for the agents working in their call center were of being generally challenging but rewarding.

\subsection{Job Design}

In terms of the job design varaibles, Table 2 sets out the means and standard deviations for each variable. Despite the differences in means, usually in the expected direction, Kruskal-Wallis one-way analysis of variance by ranks [15] revealed no statistically significant differences across the four call centers ( $\mathrm{p}>.05)$.

Technical service call centers reflected slightly higher perceptions of Skill Variety, Autonomy, Task Identity, and Friendship Opportunities. Dealing with Others showed no differences (either meaningful or statistical). Similarly, no differences emerged between feelings of uniformly low Supervisory Support, feelings of punitive feedback, feelings of excessive performance monitoring, and very low feelings of consultation over job content and technology purchase.

\subsection{Well-Being Variables}

In terms of the data derived from measuring the outcome or impact variables associated with well-being, table 3 sets out the means and standard deviations for Job Satisfaction, Life Satisfaction and Self Esteem. 
Table 2. Job design data

\begin{tabular}{lcccc}
\hline Variable & & \multicolumn{3}{c}{ Call Center } \\
& $\mathrm{A}(\mathrm{n}=27)$ & $\mathrm{B}(\mathrm{n}=38)$ & $\mathrm{C}(\mathrm{n}=42)$ & $\mathrm{D}(\mathrm{n}=33)$ \\
\multicolumn{1}{c}{$\quad$ Means (Std.Dev.)] } & & & & \\
\hline Performance Monitoring & $1.9(0.4)$ & $2.1(0.3)$ & $1.6(0.7)$ & $1.4(0.3)$ \\
Supervisory Support & $1.4(0.3)$ & $1.7(0.5)$ & $1.1(0.9)$ & $1.0(0.4)$ \\
Performance Feedback & $1.6(0.6)$ & $1.9(0.7)$ & $1.5(0.7)$ & $1.4(0.3)$ \\
Consultation about Job & $1.2(0.3)$ & $1.2(0.4)$ & $1.0(0.1)$ & $1.0(0.2)$ \\
Consultation about Technology & $1.3(0.2)$ & $1.1(0.3)$ & $1.0(0.1)$ & $1.0(0.1)$ \\
JCI & & & & \\
Skill & $2.5(0.4)$ & $2.7(0.6)$ & $2.1(0.8)$ & $2.2(0.9)$ \\
Task Variety & $2.8(0.9)$ & $2.9(0.8)$ & $2.4(0.9)$ & $2.0(1.0)$ \\
Autonomy & $2.9(1.0)$ & $3.0(1.1)$ & $2.2(0.9)$ & $1.9(0.9)$ \\
Dealing with Others & $2.6(0.9)$ & $2.8(0.9)$ & $2.6(0.5)$ & $2.4(0.9)$ \\
Friendship Opportunities & $2.9(1.1)$ & $3.1(1.2)$ & $2.2(0.9)$ & $2.0(0.8)$ \\
Feedback & $2.4(0.5)$ & $2.9(0.7)$ & $2.6(0.6)$ & $2.3(0.4)$ \\
\hline
\end{tabular}

Table 3. Well-being data

\begin{tabular}{lcccc}
\hline \multicolumn{1}{c}{ Variable } & \multicolumn{3}{c}{ Call Center } \\
\multicolumn{1}{c}{$\quad \mathrm{A}(\mathrm{n}=27)$} & $\mathrm{B}(\mathrm{n}=38)$ & $\mathrm{C}(\mathrm{n}=42)$ & $\mathrm{D}(\mathrm{n}=33)$ \\
\hline Intrisic Job Satisfaction & & & \\
Extrinsic Job Satisfaction & $2.8(0.9)$ & $2.7(0.9)$ & $2.6(0.7)$ & $2.5(0.9)$ \\
Life Satisfaction & $3.2(0.9)$ & $3.3(0.8)$ & $2.9(0.9)$ & $2.8(1.0)$ \\
Self Esteem & $3.5(1.1)$ & $3.4(0.9)$ & $3.6(1.2)$ & $3.5(1.1)$ \\
& $3.8(0.9)$ & $4.0(0.7)$ & $3.8(0.8)$ & $3.7(0.8)$ \\
\hline
\end{tabular}

Once again, despite the differences in means, again, usually in the expected direction, Kruskal-Wallis one-way analysis of variance by ranks [15] revealed no statistically significant differences across the four call centers ( $p>.05)$.

There was no meaningful or statistical difference in moderate levels of extrinsic job satisfaction, but, though not statistically significant, intrinsic job satisfaction was higher for technical call centres and lowest, together with skill variety, autonomy and task identity, for the script directed mass service call centre.

There was no difference between good positive levels of self-esteem across all four groups. However relationships (correlation coefficients not reported here) between Job Satisfaction, Life Satisfaction and Self-Esteem were not significantly different between groups, suggesting a similar pattern of context free self worth for each group.

\subsection{Supplementary Interviews}

The general findings were consistent with follow up interviews with sub samples of call center agents who had participated in the questionnaire study. Most insightful 
answers came in response to questions directed at the supportive developmental role of performance feedback and the role of the supervisor. One such response, taken from an agent working in call center $\mathrm{D}$, the scripted mass service center was;

"I don't generally see my supervisor to talk to unless she wants to moan at me. When she comes over or calls me over it's to tell me that I'm not taking enough calls or I'm too slow. She doesn't need to tell me this. I know this because she wants now to talk to me."

An agent from call center B, adds to the insight when asked about the same aspects of their relationship with his supervisor and performance feedback by this statement;

"We are supposed to get regular feedback on our performance - once a week we are supposed to meet as a group - but we are not allowed to log off together so we never meet as a group. Every week we are shown the computer times for our calls, and that kind of thing. I don't memorise mine. I just get on with what I do."

An agent from call center A (servicing the technical needs of retail clients), when asked about the level of consultation over the job content or about the technical equipment used, had the following observation;

"I was once asked about the little ear plug and mike stuff. But it didn't make any difference because we got the ones that no one liked. Mostly we are expected to get on with it. That's all."

\section{Discussion and Concluding Comments}

The findings present a picture of close supervisory control and performance monitoring common to each call center. Interview data points to a gulf between what supervisors portray - at least to interviewers from an academic institution - and their practices; at least as reflected by the low mean scores and small standard deviations of all key questionnaire data, as well as the more robust comments of the sub sample of agents interviewed.

Agents typically reflect responses that indicate, low skill variety, even in the high commitment service call centers (A and B), with each of the four samples of agents reflecting modest to low feelings of autonomy and task identity.

Feelings of Job Satisfaction, and the context free measures of Life Satisfaction and Self Esteem, show good to strong positive feelings amongst agents from all four call centers. The findings do not fit neatly into the Tayloristic - Empowerment continuum but point to individuals being able to form a dissociation or recognition that although they work in an unfavourable work environment - one in which self-actualisation might not be a deliberate or sought after goal - it does not negate the larger feelings of self worth that come from doing a dispiriting job to the best of ones' abilities.

Moreover, though the levels of Intrinsic Job Satisfaction are moderate, the higher levels of Extrinsic Job Satisfaction across all four call centers suggest that the extrinsic value of work, together with other aspects of life, reinforce the feelings of self worth. It must also be considered that, at the time that the research was conducted, the South African domestic economy was in expansion, yet unemployment rates amongst the less well educated are high. In such times, having a job is prestige, and of itself fuels self belief and self worth. 
Findings show support for the view that the pervasive application of call centre technology In South Africa attracts a managerial and supervisory disposition that is Tayloristic in its root and this seems to be so whether the conceptual service model is of the massed market type or high commitment service type.

\section{References}

1. Fullagar, C.: Organisational Behaviour in South Africa: An Historic Overview. In: Barling, J., Fullagar, C., Bluen, S. (eds.) Behaviour in Organisations. South African Perspectives, 2nd edn., McGraw-Hill, Johannesburg (1986)

2. Holman, D.: Call Centres. In: Holman, D., Wall, T.D., Clegg, C.W., Sparrow, P., Howard, A. (eds.) The Essentials of the New Workplace. A Guide to the Human Impact of Modern Working Practices. Wiley, Chichester (2005)

3. Batt, R.: Strategic Segmentation in Front Line Services: Matching Customers, Employees and HRM Systems. Int. J. Hum. Res. Mgmt. 11, 540-561 (2000)

4. Batt, R., Moynihan, L.: The Viability of Alternative Call Centre Production Models. In: Deery, S., Kinnie, N. (eds.) Call Centres and HRM Management: A Cross-National Perspective, MacMillan, Basingstoke (2004)

5. Frenkel, S., Tam, M., Korczynsky, M., Shire, K.: Beyond Bureaucracy? Work Organisation in Call Centres. Int. J. Hum. Res. Mgmt. 9, 957-979 (1998)

6. Batt, R.: Managing Customer Services: Human resources Practices, Quit Rates and Sales Growth. Acad. Mgmt. 45, 587-597 (2002)

7. Houlihan, M.: Tensions and Variations in Call Centre Management. In: Deery, S., Kinnie, N. (eds.) Call Centres and HRM Management: A Cross-National Perspective, MacMillan, Basingstoke (2004)

8. Chalykoff, J., Kochan, T.A.: Computer-Aided Monitoring: Its Influence on Employee Job Satisfaction and Turnover. Personel. Psyc. 42, 807-829 (1989)

9. Cook, J.D., Hepworth, S.J., Wall, T.D., Warr, P.B.: The Experience of Work. A Compendium and Review of 249 Measures and Their Use. Wiley. London (1981)

10. Sims, H.P., Szilagyi, A.D., Keller, R.T.: The Measurement of job Characteristics. Acad. Mgmt. J. 19, 195-212 (1976)

11. Warr, P.B., Cook, J.D., Wall, T.D.: Scales for the Measurement of Some Work Attitudes and Aspects of Psychological Well-Being. Occup. Psyc. 43, 95-109 (1979)

12. Diener, E., Emmons, R.A., Larsern, R.J., Griffin, S.: The Satisfaction with Life Scale. J. Pers. Assmt. 49, 71-75 (1985)

13. Rosenberg, M.: Society and the Adolescent Self-Image. Princeton University Press, Princeton, N.J (1965)

14. Christensen, L.B.: Experimental Methodology, 9th edn. Allyn and Bacon, Boston (2004)

15. Siegel, S., Castellan, N.J.: Nonparametric Statistics for the Behavioral Sciences, 2nd edn. McGraw-Hill, New York (1988) 